\title{
Interaction of Normal Blood Glucose Level with Mouth Shape
}

\author{
Muhammad Kashan Javed, Muhammad Imran Qadir* \\ Institute of Molecular Biology and Biotechnology, Baha Uddin Zakariya University, Multan, Pakistan
}

Received: March 26,2019; Accepted: May 16,2019; Published: May 23, 2019

*Corresponding author: Dr. Muhammad Imran Qadir, Institute of Molecular Biology and Biotechnology, Baha Uddin Zakariya University, Multan, Pakistan; E-mail: kashanjaved01@gmail.com

\begin{abstract}
A investigation was established to locate the association of regular blood glucose level with the shape of mouth. Approximately 200 persons were partook in the current survey. For the measurement of blood glucose level, we took digital glucometer then we took the blood of 200 subjects for the measurement of fasting blood glucose level. We took drop of blood from 200 persons with the glucometer which gave us their blood sugar level It was obvious that the regular level of blood glucose had scientific interaction with the shape of mouth because the value of $p$ is lower than 0.05 that's why the result was significant.
\end{abstract}

Keywords: Glucose, Blood, Association

\section{Introduction}

Blood glucose is concentration of glucose or sugar present in the blood of person. The normal mechanism of blood sugar is that insulin sustain the concentration of glucose in the body. The person who uses sugar in excess suffer high blood glucose level in his/her body called diabetes. Diabetes is actually not a disease it is a condition which can be controlled by an individual[1]. The person with high sugar in blood has to walk in order to maintain the blood sugar level. Diabetes causes several diseases if not controlled [2].

There are various forms of mouth like laughing mouth, Sad mouth, Aggressive Mouth, Serious mouth, But the most common forms are oval shaped mouth and round shaped mouth. The person who laughs every time is called Person with laughing mouth. The person who remains sad is called sad mouth person or the person with aggressiveness is called aggressive mouth. Person with angry mouth is called angry mouth person. The most common forms of mouth are oval mouth shape or round mouth shape. The person with oval shaped mouth is called oval shaped mouth and the person with round mouth shape are called round shape mouth

\section{Material and Method}

Approximately 200 persons were partook in the current survey.

For the measurement of blood glucose level, we took digital glucometer then we took the blood of 200 subjects for the measurement of fasting blood glucose level. We took drop of blood from 200 persons with the glucometer whose blood glucose level has been measured.

An investigation was established to locate the association of regular blood glucose level with the shape of mouth.

\section{Statistical Analysis}

Statistical investigation was done with the help of t-Test and MS-Excel

\section{Result and Discussion}

Association of normal level of blood glucose in relation to shape of mouth was provided in Table 1. it was obvious from Table 1 that the regular level of blood glucose had scientific relation with the shape of mouth.

A investigation was established to find the association of normal level of blood glucose and the shape of mouth.

Table 1: Normal Level of Blood Glucose In Respect To Shape of Mouth (Average $\pm \mathrm{SD}$ )

\begin{tabular}{|l|c|c|c|}
\hline \multicolumn{1}{|c|}{ Gender } & Round Shape Mouth & $\begin{array}{c}\text { Oval Shape } \\
\text { Mouth }\end{array}$ & P-Value \\
\hline Male & $93.23 \pm 7.38$ & $90.50 \pm 3.50$ & 0.23 \\
\hline Female & $93.30 \pm 9.62$ & $89.38 \pm 5.97$ & $0.01^{*}$ \\
\hline Combined & $93.26 \pm 0.04$ & $89.94 \pm 0.79$ & 0.009 \\
\hline \multicolumn{2}{|l|}{$\left(^{*} p<0.05\right.$ hence considered as significant) } \\
\hline
\end{tabular}

\section{Conclusion}

It was obvious that the regular level of blood glucose had scientific interaction with the shape of mouth because the value of $\mathrm{p}$ is lower than 0.05 that's why the result was significant.

\section{References}

1. Aisenberg S, Chang K, inventors; Whittaker Corp, assignee. Blood glucose level monitoring-alarm system and method therefor. United States patent US. 1974;3837339.

2. Longstreth Jr WT, Inui TS. High blood glucose level on hospital admission and poor neurological recovery after cardiac arrest. Annals of Neurology: Official Journal of the American Neurological Association and the Child Neurology Society. 1984;15(1):59-63. 
3. Le Bihan D. Looking into the functional architecture of the brain with diffusion MRI. Nature Reviews Neuroscience. 2003;4(6):469-480.

4. Borg G, Linderholm H. Perceived exertion and pulse rate during graded exercise in various age groups. Acta Medica Scandinavica. 1967;181(S472):194-206.

5. Qadir MI, Javid A. Awareness about Crohn's Disease in biotechnology students. Glo Adv Res J Med Medical Sci, 2018;7(3):062-064.

6. Logothetis NK. The underpinnings of the BOLD functional magnetic resonance imaging signal. Journal of Neuroscience. 2003;23(10):39633971. Doi: 10.1523/JNEUROSCI.23-10-03963.2003

7. Qadir MI, Saleem A. Awareness about ischemic heart disease in university biotechnology students. Glo Adv Res J Med Medical Sci. 2018;7(3): 059-061.
8. Qadir MI, Ishfaq S. Awareness about hypertension in biology students. Int J Mod Pharma Res. 2018;7(2): 08-10.

9. Qadir MI, Mehwish. Awareness about psoriasis disease. Int J Mod Pharma Res. 2018;7(2):17-18.

10. Qadir MI, Shahzad R. Awareness about obesity in postgraduate students of biotechnology. Int J Mod Pharma Res. 2018;7(2):14-16.

11. Qadir MI, Rizvi M. Awareness about thalassemia in post graduate students. MOJ Lymphology \& Phlebology, 2018;2(1):14-16.

12.Qadir MI, Ghalia BA. Awareness survey about colorectal cancer in students of $M$. Phil Biotechnology at Bahauddin Zakariya University, Multan, Pakistan. Nov Appro in Can Study. 2018;1(3):NACS.000514.2018. 